\title{
Influencing Factors on Vehicles Lateral Stability on Tunnel Section in Mountainous Expressway under Strong Wind: A Case of Xi-Han Highway
}

\author{
Lu Wang, ${ }^{1}$ Xiaoxin Chen $\mathbb{D}^{2},{ }^{2}$ and Hong Chen ${ }^{1}$ \\ ${ }^{1}$ College of Transportation Engineering, Chang'an University, Xi'an 710064, China \\ ${ }^{2}$ School of Highway, Chang'an University, Xi'an 710064, China \\ Correspondence should be addressed to Xiaoxin Chen; chenxiaoxin@chd.edu.cn
}

Received 22 February 2020; Revised 26 May 2020; Accepted 2 June 2020; Published 17 June 2020

Academic Editor: Chunshun Zhang

Copyright (c) $2020 \mathrm{Lu}$ Wang et al. This is an open access article distributed under the Creative Commons Attribution License, which permits unrestricted use, distribution, and reproduction in any medium, provided the original work is properly cited.

When a car is running at high speed, the canyon wind at the bridge-tunnel junction in the mountainous area brings along the acceleration effect. The aerodynamic lateral force will cause the vehicle sideslip and unsteady steering, which is extremely harmful to driving safety. In this paper, Xi-Han Expressway is taken as the research object to analyze the influencing factors of vehicle's lateral stability by combining the theoretical research of the finite element method, automobile aerodynamics, and speed limit with field investigation and simulation test. CarSim software is used for simulation to explore the influence of different positions of the circular curve on vehicle lateral stability. The results show that the wind level affects the tunnel exit's unfavorable section on the circular curve. The larger the wind level, the larger the proportion of the tunnel exit's unfavorable section on the circular curve. The proportions of tunnel exit's unfavorable section on the circular curve under 6-9 wind levels are 33.33\%, 38.89\%, 55.56\%, and $66.67 \%$, respectively. In addition, the lateral stability of vehicles under level 6-8 wind scale is the worst when the tunnel exit is located at $5^{\circ}$ position on the circular curve. The results indicate the influence of strong wind on the lateral stability of vehicles in mountainous expressway. The research can optimize the design of the highway tunnel group and provide the basic theory and method basis for the quantitative management and scientific management of the road traffic management department.

\section{Introduction}

The expressway occupies an important position in China's road construction system. With the rapid growth of China's road construction, by the end of 2016, there were 805,300 bridges with a total length of 49,169,700 meters and 15181 tunnels with a total length of 14,039,700 meters. The rapid development of road infrastructure has greatly improved road capacity and transportation efficiency.

Under the policy of "the belt and road," the highway construction is developing towards mountainous areas, especially under the vigorous economic development of northwestern China in recent years. In the construction of mountainous highways, bridges and tunnels are the main means to optimize the road alignment and shorten the driving mileage, which occupy a large proportion of the mileage of mountainous highways. The improvement of China's road network and the increasing mileage of road infrastructure enlarged the service scope and technical level of China's road network, effectively improved transportation efficiency, and promoted the development of national economy. But there are also many problems, especially traffic accidents. There are about 4.7 million traffic accidents occurring every year, of which more than 200,000 casualties account for $21 \%$ of the wounded. Especially in the mountainous areas where the road alignment is not good and the bends are too sharp, highway accidents are more likely to happen. For example, in the Xi'an section of the Xi-Han Expressway in 2007-2013, the cumulative traffic accidents resulted in 123 casualties.

In the course of the development of modern traffic construction, more and more researchers pay great attention 
to study the influence of complex meteorological conditions on transportation. The conclusion is that complex meteorological conditions lead to poor driving stability [1-3]. Driving vehicles are prone to lateral flip and sideslip under strong wind [4]. Scholars at home and abroad carry out researches on long span bridge $[5,6]$, expressway $[7,8]$, railway $[9,10]$, and other transportation situation from the perspective of aeromechanics. There are a lot of research results that have been put forward by scholars on the vehicles' driving safety and stability under strong wind [11-15]. At the mountainous expressway tunnel area, the traffic safety problem is increasingly prominent due to the changeable environment condition and the unstable traffic flow speed, causing great influence on the transportation environment. The vehicles driving on mountainous highways are susceptible to the influence of canyon crosswind, which causes weak driving instability, and is a problem often encountered in mountainous expressway areas [16-18].

In 1990s, with the development of relevant theories and technical methods, more and more advanced technology and algorithms are used in the study of tunnel traffic flow theory, and the monitoring measures of tunnel traffic are constantly improved [19-21]. By analyzing the relationship between tunnel traffic flow and tunnel environment, some domestic scholars reveal the distribution characteristics of tunnel traffic accidents and give the corresponding prevention strategies [22-24]. In the area of tunnel safety, foreign agencies have carried out research on traffic accidents involving injuries in highway tunnels $[20,25,26]$. In the study of the geometrical characteristics of tunnels, foreign scholars have come to the conclusion that the acceleration-deceleration of vehicles in tunnels is asymmetric. Based on the research on the Qinling Highway tunnel group, Song [27] analyzed the influence of different tunnel linearity on traffic safety and puts forward better linear design of the tunnel group. For the application of mountainous tunnel linearity, foreign scholars generally only apply the theory of road traffic flow to tunnel operation and management, while less study of linear design on the mountainous tunnel group has been made and applied to the traffic safety aspect. In the mountain canyon area, due to the influence of terrain, strong wind is more common, which is easy to pose a threat to the safety of vehicles $[28,29]$. The radius of circular curves at different design speeds has been stipulated by the book of "Design Specification for Highway Route" (2017), but the influence of tunnel group crosswind on vehicle's driving safety has not been considered.

Vehicles driving on bridge-tunnel junctions of mountain expressways are often affected by strong wind. On the contrary, the benchmark that China has adopted is "Design Specification for Highway Route" which does not consider how the wind influences driving safety. It increases the accident rate in this area. Furthermore, the canyon wind causes the acceleration effect which suggests that evaluating the driving safety under strong wind in canyon is critical. This article aims to deliberate the facts that wind affects the driving safety in mountainous highways to reduce the accident rates and provide the fundamental exercise for further design and operation. The data from the Xi-Han High Speed
Observation Station was used to study the influence of vehicle speed, radius of the circular curve, distance between tunnels, and the position of the tunnel exit on the circular curve on the driving safety of vehicles, and the CarSim simulation method is used to determine the most adverse tunnel exit location and section on the circular curve. The results can provide a basis for the design and operation of mountain highways.

\section{Case of the Data}

The Xi-Han Highway is a part of G5 national highway network which is located in Shanxi province. It is also a main part of the Shanxi's road system. The overall length of the XiHan Highway is $635 \mathrm{~km}$ and passes through cities such as Weinan, Xi'an, Ankang, and Hanzhong. It has 24 tunnels, 15 flyovers, and 69 bridges, and the tunnel in the Qinling Mountains is $18 \mathrm{~km}$, which even has over 20 huge bridges. Due to the natural environmental condition in this area, the highway has high percentage of bridges and tunnels which make the road having large slopes and sharp turns. The climatic zone, which is called warm temperate humid monsoon, controls this area, and complicated geomorphology conditions are a reason for traffic accidents in this area. Regardless of the individual fault in these accidents, the most crucial objective factor is wind, especially in June and July.

To support this article research point, a traffic survey in a highway tunnel which has a windy affection for driving is conducted in the Xi-Han Highway. It sets up a sample that first and third lanes are upstream and that second and fourth lanes are downstream. The traffic flows, driving speed, and road occupancy are recorded in this sample.

15 observation points were constructed to gather related driving data. The mileage point numbers are K1101.300, K1117.300, K1118.300, K1131.300, K1132.300, K1142.600, K1154.650, K1157.000, K1158.000, K1176.000, K1188.400, K1222.000, K1223.000, K1263.500, and K1265.000, which have been separately tested on 28 July 2017 and 16 March 2018 with 5 minutes periodic time. According to the meteorological data, strong wind with above scale 5 occurred on 28 July 2017; it resulted in wreckage of road-side trunks. Hence, data from 28 July 2017 and 16 March 2018 were adopted to analyze.

The traffic survey uses radar speed measurement that the fundamentals are based on the Doppler effect: radar speed detectors bounce microwave radiation of moving vehicles off and detect the reflected waves. These waves are shifted in frequency, and the frequency difference between the directed and reflected waves provides a measure of the present vehicle speed.

The measurement provided 30 groups of data on 16 March 2018 and 28 July 2017. The analysts conducted vertical comparison with the 15 groups of data that were collected on the same day and a horizontal comparison with the two days data from a mileage point. Based on the effect of road alignment and other aspects, this paper divides the data into high level, middle level, and low level. For instance, the mileage point K118.300 has an average speed of $120 \mathrm{~km} / \mathrm{h}$ 
which is impracticable, and the mileage point K1188.400 has more than $30 \%$ of zero speed. On the basis of research orientation, based on the same or similar horizontal and vertical slopes, the data collected from K.1131.300, K1131.300, K1142.600, K1154.000, K1158.000, and K1176.000 have been selected for analyzing. Meanwhile, according to the pattern of the traffic flow from the Xi-Han Highway, the data of time from 10 a.m. to 9 p.m. with high traffic density are selected as object of study of the high-level data.

2.1. Vehicle's Driving Speed Affected under Strong Wind. The sideslip and even rollover accidents are more likely to occur to the vehicles on complex roads under strong wind, which is challenging the comfort, stability, and driving safety. Under the effect of strong wind, drivers lose the correct judgement of direction, tend to reduce the speed, and change the line. The following data are collected and analysed by the survey of the Xi-Han Highway.

Table 1 clearly shows that the average speed on various mileage points on 28 July is relatively slower than that on 16 March. On 28 July, K1131.3, K1132.3, and K1142.6 stated the average speed was $88.621 \mathrm{~km} / \mathrm{h}, \quad 83.755 \mathrm{~km} / \mathrm{h}$, and $57.529 \mathrm{~km} / \mathrm{h}$ and reduced $10.5 \%, 9 \%$, and $11.9 \%$, respectively, to average speed on $16 \mathrm{March}$. It demonstrates that the impact has significantly increased at tunnels, and thus the speed changes would be greater. Table 2 shows that vehicles travelled on 28 July had lower average speed compared to that on 16 March at point K1142.6. This indicates that under the same circumstance, regardless of the vehicle model and road condition, the wind scale and vehicle speed have negative relation.

\subsection{Difference of Vehicle's Driving on Tunnel Groups and} Ordinary Roads under Wind Condition. This paper takes lateral acceleration and lateral force coefficient as key factors to evaluate driving vehicle's lateral stability. It compares and analyzes vehicle's driving behavior on tunnel groups and ordinary roads under wind condition. The definition and threshold value of these indicators are shown in Table 3.

Take the same curve radius and lateral and longitudinal slope scale as the basis of selection and set the tunnel exit curve at the point K1143 and ordinary road at K1176 as the object of evaluation. The data collected from these two points fulfill the requirement of radius curvature equal to $260 \mathrm{~m}$ with lateral slope of $11 \%$ and longitudinal slope difference of $0.07 \%$.

Vehicle models selection: based on the statistical data that vehicle types are collected from the Xi-Han Highway, the sedan and other small cars have the most representativeness to be selected as the object of the survey. Adopt the vehicles' best seller ranking and take total length of $4442 \mathrm{~mm}$, width of $1748 \mathrm{~mm}$, height of $1466 \mathrm{~mm}$, lateral area of 6.5 square meters, and front area of 2.56 square meters as the benchmark.

The formula has been taken:

(1) Lateral force coefficient:
Table 1: Average speed under the wind.

\begin{tabular}{lccc}
\hline Date mileage point & $\begin{array}{c}28 \mathrm{July} \\
(\mathrm{km} / \mathrm{h})\end{array}$ & $\begin{array}{c}\text { 16 March } \\
(\mathrm{km} / \mathrm{h})\end{array}$ & Disparity (\%) \\
\hline K1131.3 & 88.621 & 99.054 & 10.5 \\
K1132.3 & 83.755 & 91.322 & 9 \\
K1142.6 & 57.529 & 65.282 & 11.9 \\
\hline
\end{tabular}

By the force balance analysis of the vehicle mechanics model, the ratio of lateral force and vertical force is calculated to measure the stability and safety of vehicle driving. According to Fan et al.'s study [30], the simplified expression equation is as follows:

$$
\begin{aligned}
C_{S} & =\frac{F_{y}}{F_{z}}, \\
F_{y} & =\frac{M v^{2}}{R} \cos \alpha \cos \alpha^{\prime}, \\
F_{z} & =M g \cos \alpha \cos \alpha^{\prime} . \\
\text { Hence, } C_{S} & =\frac{v^{2}}{R g},
\end{aligned}
$$

where $F_{y}$ is the lateral force from the ground to wheels, $F_{z}$ is the wheel's vertical load, $C_{S}$ is the lateral force coefficient, $\alpha$ and $\alpha^{\prime}$ are the longitudinal slope and lateral slope, respectively, and $R$ is the radius of curvature.

(2) Lateral acceleration:

When the vehicle is affected by lateral force or lateral moment, the vehicle will roll and the roll angle will increase with the increase of lateral acceleration. The vertical load of the inner wheel tire will be smaller, and the vertical load of the outer tire will be larger. When the lateral acceleration increases to the threshold limit, the inner wheel will leave the ground and the vehicle will roll over. According to reference [31], lateral acceleration can be obtained as follows:

$$
\text { without wind, } a_{y}=\frac{v_{\mathrm{car}}^{2}}{R} \text {. }
$$

The vehicle will be affected by the lateral aerodynamic force under crosswind. Wang [16] proposed the calculation formula to get the lateral acceleration of the vehicle under crosswind, which is simplified as follows:

$$
\text { with wind, } a_{y}=\frac{v_{\text {car }}^{2}+v_{\text {wind }}^{2}}{R} \text {. }
$$

The vehicle's average speed at K1143 has been collected on 28 July and 16 March and at K1176 on 28 July, and Tables 4 and 5 show the calculation of the lateral force coefficient and lateral acceleration. 
Table 2: Average speed of K1142.6 at 10 a.m. to 9 p.m.

\begin{tabular}{|c|c|c|c|c|}
\hline \multirow{2}{*}{ K1142.6 time } & \multicolumn{2}{|c|}{28 July $(\mathrm{km} / \mathrm{h})$} & \multicolumn{2}{|c|}{$16 \operatorname{March}(\mathrm{km} / \mathrm{h})$} \\
\hline & First and third & Second and fourth & First and third & Second and fourth \\
\hline 10:00-11:00 & 56.879 & 51.236 & 53.840 & 54.720 \\
\hline $11: 00-12: 00$ & 62.951 & 47.831 & 61.326 & 61.957 \\
\hline $12: 00-13: 00$ & 58.661 & 54.373 & 61.739 & 62.348 \\
\hline $13: 00-14: 00$ & 60.794 & 55.256 & 64.370 & 65.848 \\
\hline $14: 00-15: 00$ & 61.372 & 57.061 & 72.478 & 73.022 \\
\hline $15: 00-16: 00$ & 63.725 & 55.633 & 73.326 & 73.522 \\
\hline $16: 00-17: 00$ & 64.482 & 56.207 & 71.739 & 72.326 \\
\hline $17: 00-18: 00$ & 62.711 & 54.273 & 72.304 & 72.239 \\
\hline 18:00-19:00 & 62.197 & 53.881 & 70.348 & 70.978 \\
\hline 19:00-20:00 & 60.194 & 54.851 & 72.022 & 72.311 \\
\hline 20:00-21:00 & 62.263 & 52.355 & 71.891 & 72.174 \\
\hline 21:00-22:00 & 60.916 & 52.759 & 72.239 & 72.174 \\
\hline
\end{tabular}

TABLE 3: Evaluation standards.

\begin{tabular}{|c|c|c|c|}
\hline Evaluation standards & Contents & Threshold & Notes \\
\hline $\begin{array}{l}\text { Lateral acceleration } \\
\left(a_{y}\right)\end{array}$ & $\begin{array}{l}\text { Vehicles are under the effect of lateral force while passing the curve. The wind would } \\
\text { increase the force to generate lateral acceleration. }\end{array}$ & $a_{y} \leq 0.4 \mathrm{~g}$ & \\
\hline $\begin{array}{l}\text { Lateral force } \\
\text { coefficient }\left(C_{S}\right)\end{array}$ & $\begin{array}{l}\text { The equal lateral force on different vehicles has different degree of stability. The lateral } \\
\text { force coefficient taking the total lateral momentum over the vertical momentum to } \\
\text { evaluate the safety, stability, and comfort when vehicles driving on the curve. It is similar } \\
\text { to the lateral force applied on the vehicle. }\end{array}$ & $C_{S} \leq 0.4$ & $\begin{array}{l}C_{S}>0.17 \\
\quad \text { slip } \\
C_{S}>0.4 \text { roll }\end{array}$ \\
\hline
\end{tabular}

TABLE 4: Lateral force coefficient and lateral acceleration at K1143.

\begin{tabular}{lcc}
\hline Mileage point: K1143 & 28 July & 16 March \\
\hline Average lateral acceleration $\left(\mathrm{m} / \mathrm{s}^{2}\right)$ & 1.409 & 1.072 \\
Percentage of lateral force coefficient that is more than $0.17(\%)$ & 24.40 & 5.60 \\
\hline
\end{tabular}

TABLE 5: Lateral force coefficient and lateral acceleration at K1176.

\begin{tabular}{lc}
\hline Mileage point: K1176 & 28 July \\
\hline Average lateral acceleration $\left(\mathrm{m} / \mathrm{s}^{2}\right)$ & 1.28 \\
Percentage of lateral force coefficient that is more than & 21.00 \\
$0.17(\%)$ & \\
\hline
\end{tabular}

Abstracting from Table 4 that at the K1143 tunnel exit, average lateral acceleration on 28 July was $1.409 \mathrm{~m} / \mathrm{s}^{2}$, $0.337 \mathrm{~m} / \mathrm{s}^{2}$ higher than that on $16 \mathrm{March}$. During 8 a.m. to 9 p.m., the percentage that $C_{s}$ is greater than threshold was $24.40 \%$ and $5.60 \%$. Obviously, the lateral acceleration would be greater under the windy condition, more likely to cause slips.

In conclusion of Tables 4 and 5 by comparing two mileage points on 28 July that the average lateral acceleration at $\mathrm{K} 1143$ was $0.129 \mathrm{~m} / \mathrm{s}^{2}$ higher than that at $\mathrm{K} 1176$, the percentage of $C_{s}$ that is greater than threshold was $3.4 \%$ higher during 8 a.m. to 9 p.m. Therefore, under the windy condition, driving vehicles at the tunnel entrance and exit are more likely to slip. Due to the changes in driving environment, the driving safety will drop dramatically.
2.3. Impact of Different Wind Angles to Driving Safety and Stability of Vehicles. Previous analysis suggests that under the wind condition, the lateral force coefficient and lateral acceleration would increase. In order to analyze the data from different wind angle, this paper took the average speed at K1142.6 on 28 July from 10 a.m. to 10 p.m., estimating the wind angle to be 90 degrees, 60 degrees, and 30 degrees to the driving vehicles.

Figure 1 indicates a progressively increased lateral acceleration from 30 degrees to 60 degrees to 90 degrees, with $1.081 \mathrm{~m} / \mathrm{s}^{2}, 1.274 \mathrm{~m} / \mathrm{s}^{2}$, and $1.370 \mathrm{~m} / \mathrm{s}^{2}$, respectively. Along with the degree reaching 90 , the value of $C_{s}$ will infinitely be close to threshold of slip. Hence, vehicles are affected by wind most significantly while passing the curve. The smaller the degree between angles of wind and the vehicle, the higher the safety is.

2.4. Impact of Length between Tunnels under the Same Wind Condition to Driving Safety. Based on the previous analysis, this paper took separation distances of $165 \mathrm{~m}$ between Zhuque Tunnel and Qilingyihao Tunnel and $1300 \mathrm{~m}$ between Shuangshuimo Tunnel and Zhifang Tunnel as 


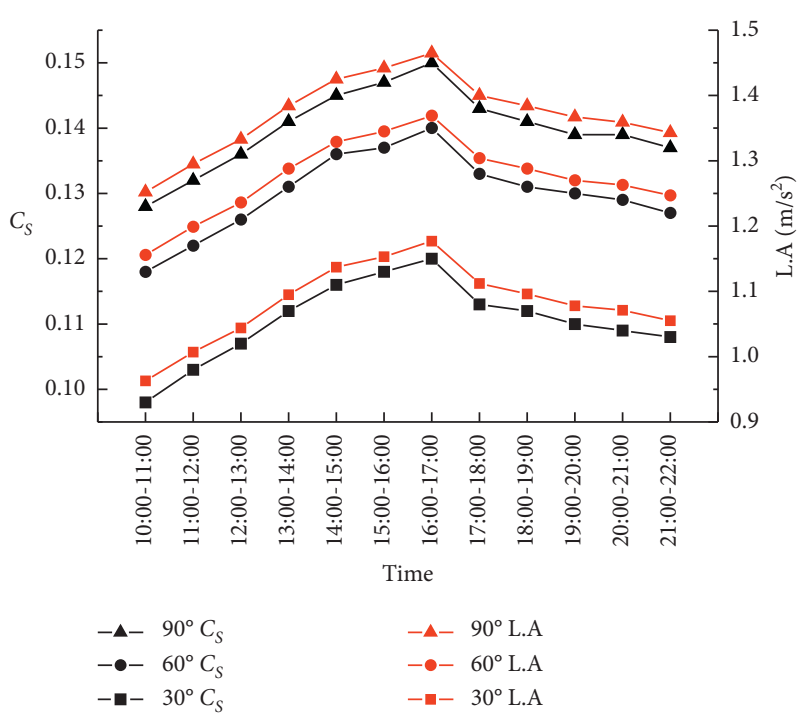

FIgURE 1: The impact of different wind angles to the lateral force coefficient and lateral acceleration.

sample to compare and evaluate. The results are shown in Figure 2 with $C_{\mathrm{s}}$ and lateral acceleration per hour at 10 a.m. to 10 p.m.

Figure 2 states that the lateral acceleration was $0.209 \mathrm{~m} / \mathrm{s}^{2}$ at K1158. There is $1.161 \mathrm{~m} / \mathrm{s}^{2}$ difference compared with that at $\mathrm{K} 1142.6$ which was $1.370 \mathrm{~m} / \mathrm{s}^{2}$. Meanwhile, the average $C_{\mathrm{s}}$ was 0.021 at K1158, and it is significantly lower compared with $C_{\mathrm{s}}$ at K1142.6 with 0.140 . This demonstrates that the lateral force coefficient is closer to the threshold of slip when the distance between tunnels is smaller. Hence, the longer the distance between tunnels, the safer the drive is.

\subsection{Impact of Tunnel Exit Located on Different Curve Radius} to Driving Safety. Based on the formula presented, the lateral force coefficient will change with the curve radius under same wind scale condition. Hence, the data collected from K1142.600 and K1154.000 have been chosen after selecting and evaluating all mileage points across the survey in order to analyze the concepts of changes between the curve radius and lateral force coefficient regardless of other aspects that may affect it.

In Figure 3, this survey chose K44 and K58 and the exit of Zhifang Tunnel and Zhuque Tunnel to analyze the average speed data to calculate and compare. It chose the typical time at 10:00-22:00 and found that in 13:00 to 18:00 time period, the average speed on each tunnel is very close. The K1142.600 point's radius of curve is $260 \mathrm{~m}$ and that of the $\mathrm{K} 1154.00$ point is $1600 \mathrm{~m}$. It is a very huge gap between these two point's data. After serious calculation, the lateral force coefficient at K1142.600 is close to the threshold of 0.17, way larger than that at K1154.000. Therefore, it can get a conclusion that on the same condition, when the tunnel's radius of curve is smaller, the lateral force coefficient is close to threshold, and the vehicles have high possibility to slip or even roll over.

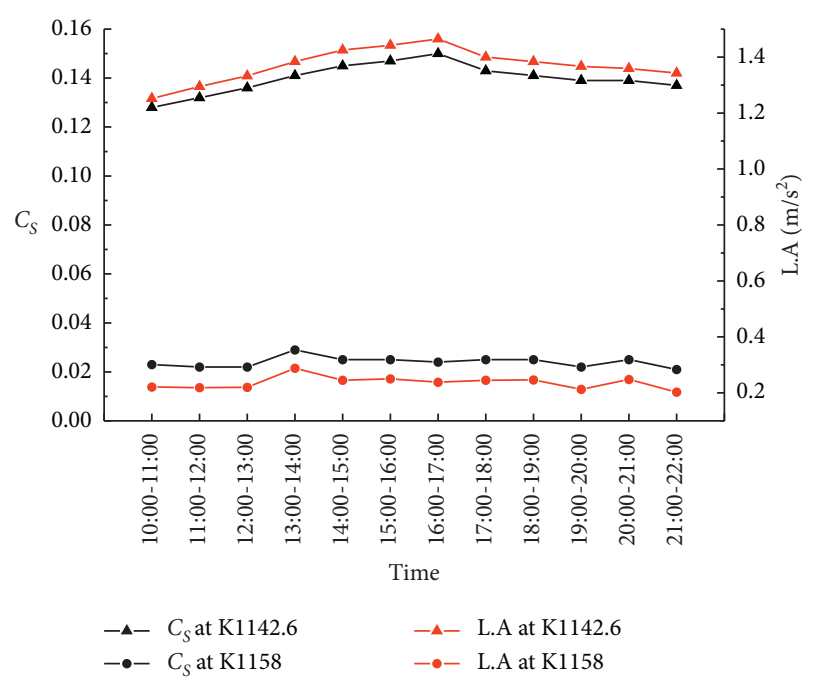

Figure 2: $C_{S}$ and lateral acceleration at K1142.6 and K1158 on 28 July.

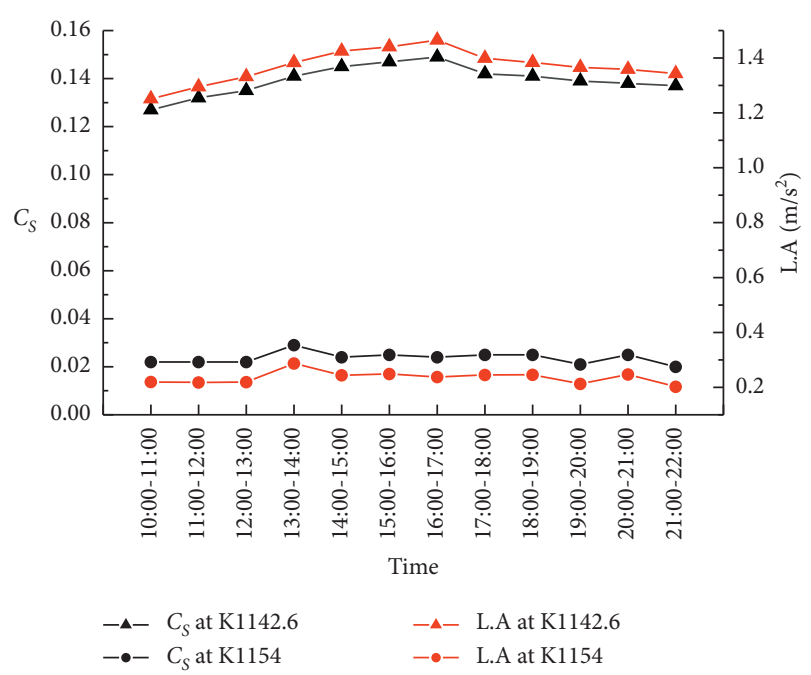

Figure 3: $C_{S}$ and lateral acceleration at K1142.6 and K1158.

The strong wind under canyon acceleration effect would generate lateral force which combines with centrifugal force. When the direction of wind and centrifugal force are the same, the combined force reaches its maximum. This frequently happened in gorge areas of highways. Take previous analysis into account that the stability of driving would be affected by the location of tunnel exit on the circular curve. The different location of tunnel exit means the combined force would apply to different location of vehicles at circular curve. In order to analyze how combined force affects the lateral stability of vehicles, the application of CarSim software would be adopted to determine the most adverse tunnel exit location and section on the circular curve to provide the theoretical basis for design of tunnel. 


\section{Simulation Analysis}

3.1. Model Building. CarSim software is used to build the vehicle model and road model to simulate the effect of crosswind in tunnels and bridges.

3.1.1. Vehicle Model Setting Up. The vehicle's parameters and the proportion influenced by wind play a role in the crosswind lateral force. The FAW-Volkswagen Jetta 180 manual gear with model number FV7150FCMBG is chosen for the simulation. This model vehicle's detail data are as shown in Figure 4 and Table 6.

3.1.2. Road Model Setting Up. The 3-dimentional road is chosen as the road model to reflect the influence of driving at different location of the circular curve on vehicle's lateral stability. For general road designing between the straight road and the circular road, there is a buffer zone to release the danger for drivers. However, the designing of these buffer zones has so many uncertain aspects. Therefore, a combination of a 200-meter straight line and a series of $90^{\circ}$ circular lines is used in the simplified model to simulate vehicle's taking turns. Because that the influence of road slope on driving stability is not considered in the model, this paper does not set the vertical parameters of road's linear section. Meanwhile, the horizontal slope of 8 degrees is chosen to build up the model, which is frequently used in mountainous highways. Figure 5 is the horizontal alignment of the road model.

3.1.3. Wind Model Setting Up. The canyon will increase the wind speed at the central position of the bridge under the same condition of wind speed and mountain environment. However, the wind speed on the entrance of the tunnel does not accelerate, due to the blockage effect. Therefore, this paper chooses the minimum data of the wind speed at the entrance of the tunnel as the best. On the contrary, it used an acceleration ratio as the parameter of wind at the central position of the bridge. As a conclusion, the separation distance is smaller, and the speedup effect of wind is greater. According to the available data, when the Xi-Han Highway canyon separation distance is 20 meters, 30 meters, or 50 meters, the wind speedup effect is $33.5 \%, 30.7 \%$, and $27.5 \%$, respectively. In order to analyze the driving stability affected by crosswind at the connecting segment of the tunnel and bridge, the typical case which has 20 meters separation distance between tunnels is chosen to simulate the speedup effect of wind.

In these tests, the windward area is set as $5 \mathrm{~m}^{2}$ and the crosswind influence point is set as $1.226 \mathrm{~m}$. Then, input the data of wind direction and wind speed which takes a linear interpolation and extrapolation as shown in Figure 6.

\subsection{Simulation Data Analysis}

3.2.1. Simulation Strategy Setting and Index Choosing. The mountain expressways with the speed limit of $80 \mathrm{~km} / \mathrm{h}$ is taken as the study object to collect data. Moreover, according to the "Design Specification for Highway Route (JTGD202017)," the maximum horizontal slope rate of the circular curve should be applied as 8 degrees in this paper, and the circular minimum radius should be greater than 250 meters. The simulation input of this paper is as follows:

Speed: $80 \mathrm{~km} / \mathrm{h}$

Road's lane setting: $200 \mathrm{~m}$ straight line and $90^{\circ}$ circular curve which radius 250 meters

Road's vertical parameter: none

Road's horizontal slope rate: 8 degrees

Length of separation distance between tunnels: 20 meters

The general wind speed is $8 \mathrm{~m} / \mathrm{s}$ and the wind scale is level 5. The maximum wind speed in the Xi-Han Highway was $31.5 \mathrm{~m} / \mathrm{s}$ in recent years, approximately $113 \mathrm{~km} / \mathrm{h}$. However, the wind scale over level 10 is a small probability event. Therefore, the wind scale is set as 5 to 9 level and the details of wind setting are listed in Table 7 . The most adverse situation is used to collect the data which can be used as threshold value for road designing. For the position where the wind acts on the circular curve, the joint segment between the circular curve and the straight line is recorded as $0^{\circ}$. The successive approximation method is used to reduce the number of simulation tests and improve test efficiency. Then, the simulation tests are carried out by taking $30^{\circ}$ as the gradient and setting the initial research position as $0^{\circ}, 30^{\circ}$, $60^{\circ}$, and $90^{\circ}$ successively. When the vehicle is unstable at a certain position, the test interval will be reduced, and the transient lateral stability of the vehicle at different positions will be studied in the instability interval with gradients of $15^{\circ}$ and $5^{\circ}$, respectively. Finally, unfavorable interval on the circular curve and the most unfavorable position of the tunnel exit are recorded in the research. Therefore, the tunnel exit should be avoided in these areas when designing.

3.2.2. Simulation Results and Analysis. The lateral acceleration and lateral force coefficient are used as the evaluation indicators of the lateral stability of the vehicle. When the results of the simulation are within the safety threshold of these two indicators, it can be determined that the vehicle has no risk of lateral instability. Otherwise, it is recognized as a risk. Under the level 5 wind scale, the instantaneous lateral acceleration of the vehicle is less than $0.4 \mathrm{~g}$, and the lateral force coefficient is also less than 0.4. Therefore, it is determined that the vehicle can drive safely under the level 5 wind scale. The simulation results of the vehicle at different positions of the circular curve which under the level 6 to 9 wind scale are presented in Figures 7 and 8.

Take the level 6 wind scale as an example, and it can be concluded from Figures 7 and 8 that as the tunnel exit moves along with driving direction on the circular curve, the values of the two indicators generally increase firstly and then decrease. Furthermore, the maximum and minimum values of the lateral acceleration are $0.367 \mathrm{~g}$ and $0.228 \mathrm{~g}$ under level 6 wind scale. Moreover, the maximum and minimum values of the lateral force coefficient are 0.437 and 0.210, 


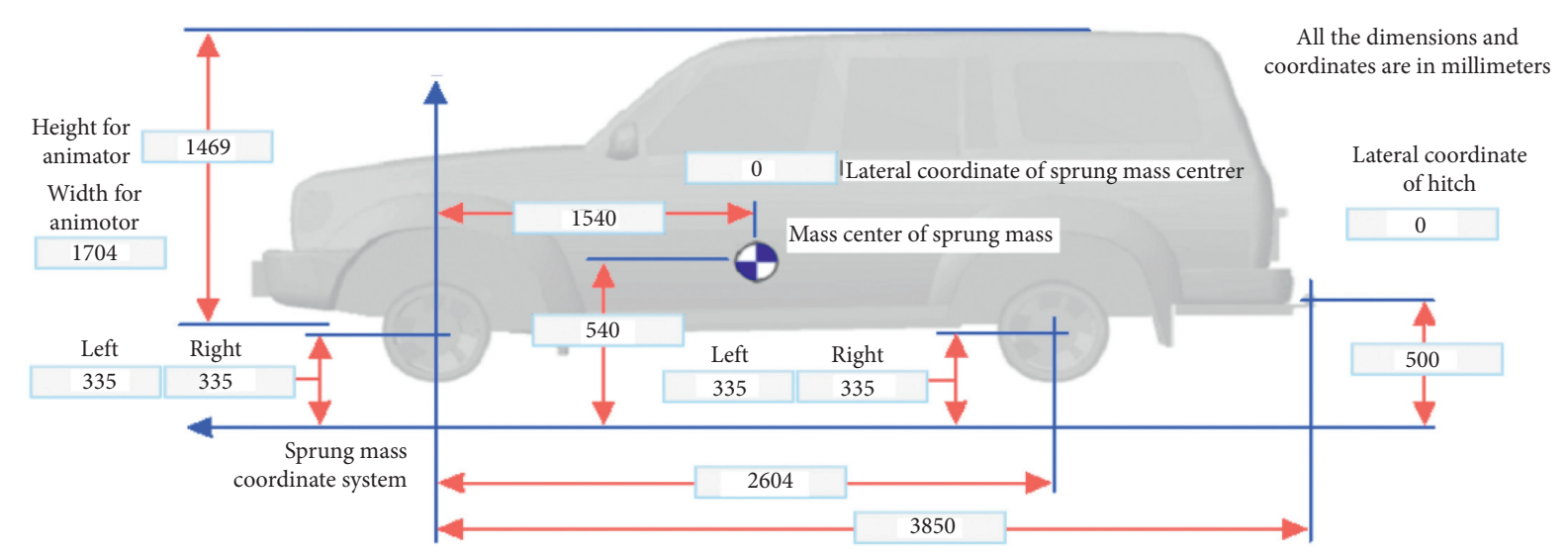

Figure 4: Vehicle parameters setting.

TABLE 6: The main parameters of model vehicle.

Parameter Length $(\mathrm{mm})$ Width $(\mathrm{mm})$ Height $(\mathrm{mm})$ Wheel base $(\mathrm{mm})$ Front overhang $(\mathrm{mm}) \quad \begin{gathered}\text { Height of center of } \\ \text { mass }(\mathrm{mm})\end{gathered}$ Sprung mass $(\mathrm{kg})$

\begin{tabular}{llllllll}
\hline Number & 4501 & 1704 & 1469 & 2604 & 1540 & 540 & 1140 \\
\hline
\end{tabular}

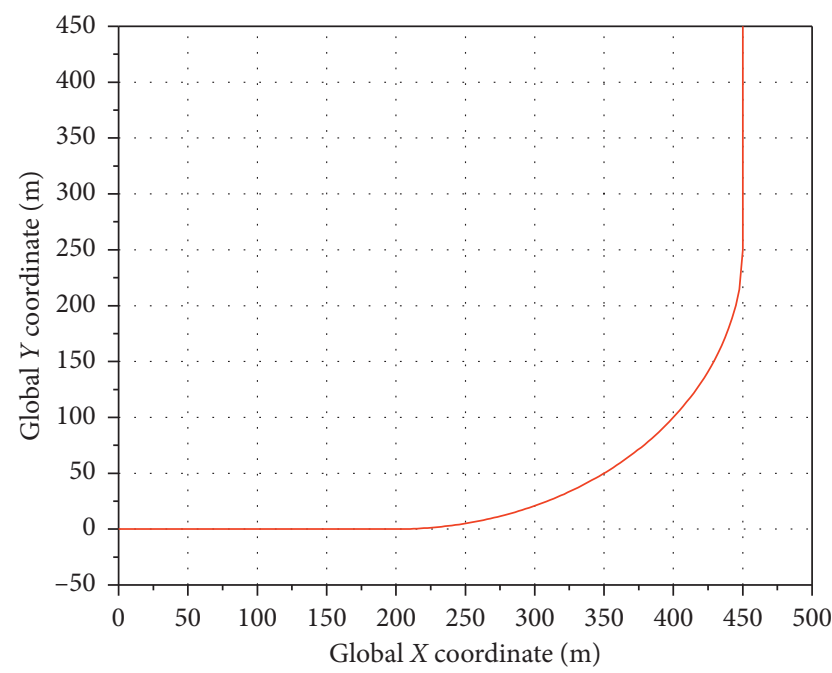

Figure 5: Plane alignment of the road model.

respectively. When the tunnel exit is at the position of $0^{\circ} \sim 30^{\circ}$, although the lateral acceleration of the vehicle does not exceed over $0.4 \mathrm{~g}$, the lateral force coefficient has exceeded the safety threshold of 0.4 . Therefore, it is determined that there is a risk of lateral stability. When the tunnel exit is at the end of the circular curve, that is $90^{\circ}$, the lateral stability of the vehicle is optimal. When the circular curve is at $5^{\circ}$, the lateral acceleration and lateral force coefficients of the vehicle reach the maximum. The data results are respectively $0.367 \mathrm{~g}$ and $0.437 \mathrm{~g}$. In summary, under the action of the level 6 wind scale, the unfavorable interval of the tunnel exit is $0^{\circ} \sim 30^{\circ}$ on the circular curve, and the most unfavorable position is on the circular curve $5^{\circ}$.

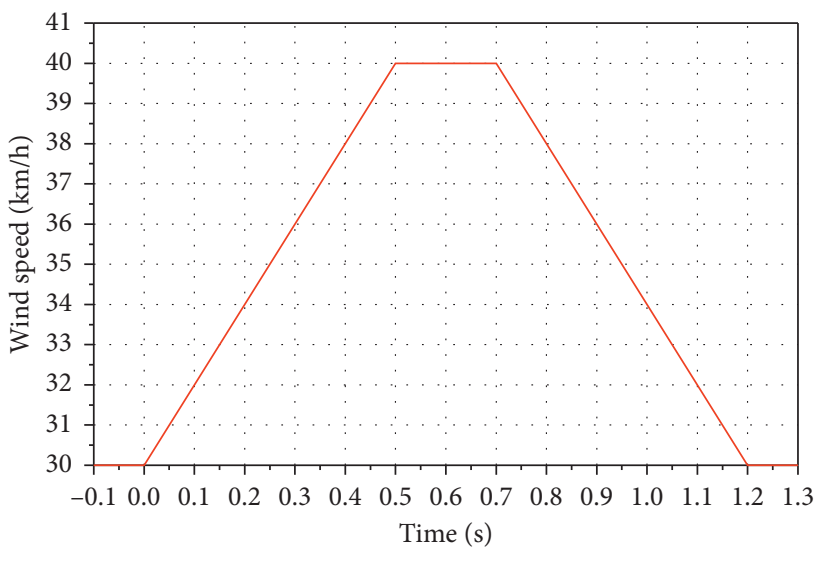

_ Linear interpolation \& extrapolation

FiguRE 6: Wind speed data setting interface.

It can also be seen from the abovementioned figures that when the wind action intensity continues to increase from level 7 to level 9, the trend of the lateral acceleration and lateral force coefficient of the vehicle is basically the same as that of the level 6 wind scale. Under level 7 wind scale, when the tunnel exit is $35^{\circ}$ at the circular curve, the lateral acceleration of the vehicle is $0.385 \mathrm{~g}$, which is within the safety threshold. However, the lateral force coefficient is 0.412 , and the safety value is only 0.4 , so the tunnel exits at the range of $0^{\circ} \sim 35^{\circ}$ of the circular curve is judged to be dangerous. In the same way, under the action of the level 8 wind scale and level 9 wind scale, the tunnel exit's unfavorable interval on the circular curve is $0^{\circ} \sim 50^{\circ}$ and $0^{\circ} \sim 60^{\circ}$, respectively. For the most unfavorable position analysis of the tunnel exit under the $7 \sim 9$ wind level, it is available from the simulation data. 
TABLE 7: Wind scale setting.

\begin{tabular}{lcc}
\hline Wind scale & $\begin{array}{c}\text { Original speed } \\
(\mathrm{km} / \mathrm{h})\end{array}$ & $\begin{array}{c}\text { Expedite speed } \\
(\mathrm{km} / \mathrm{h})\end{array}$ \\
\hline Level $5(29 \sim 38 \mathrm{~km} / \mathrm{h})$ & 30 & 40 \\
Level $6(39 \sim 49 \mathrm{~km} / \mathrm{h})$ & 40 & 52 \\
Level $7(50 \sim 61 \mathrm{~km} / \mathrm{h})$ & 52 & 67.6 \\
Level $8(62 \sim 74 \mathrm{~km} / \mathrm{h})$ & 62 & 80.6 \\
Level $9(75 \sim 88 \mathrm{~km} / \mathrm{h})$ & 75 & 97.5 \\
\hline
\end{tabular}

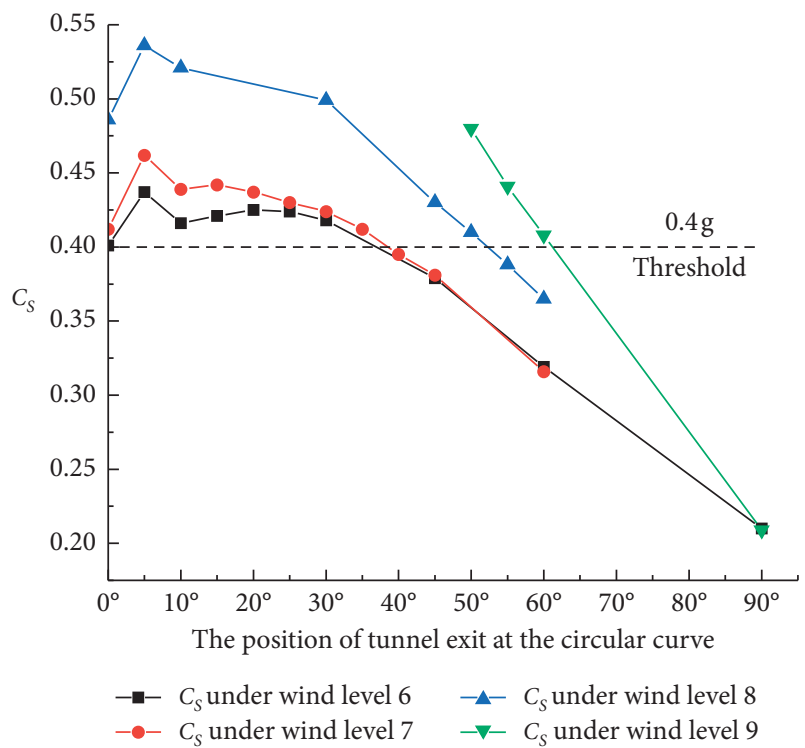

Figure 7: Lateral force coefficients of the vehicle at different positions.

Under the action of the level 7 and level 8 wind scale, the lateral acceleration and the lateral force coefficient reach the maximum at $5^{\circ}$ of the circular curve, so the tunnel exit's unfavorable position is located at $5^{\circ}$ of the circular curve, which is the same as under the level 6 wind scale. Under the action of the level 9 wind scale, when the tunnel exit is located at a circular curve of $0^{\circ} \sim 45^{\circ}$, the vehicle has rolled over, as shown in the simulation results in Figure 9. Therefore, when a section of a mountain highway is vulnerable to strong winds and the environment is relatively harsh, the tunnel exit should be strictly avoided at $0^{\circ} \sim 45^{\circ}$ of the circular curve section.

The unfavorable interval and the unfavorable position of the tunnel exit under the level 5 to level 9 wind scale on the circular curve are summarized in Table 8.

From the simulation data in Table 8 , it can be concluded that the wind level has an influence on the unfavorable position of the tunnel exit on the circular curve. From the perspective of the vehicle's lateral stability, the influence mainly starts from the level 6 wind scale. The larger wind level means the greater proportion of the tunnel exit's unfavorable interval on the circular curve, that is, the less safe

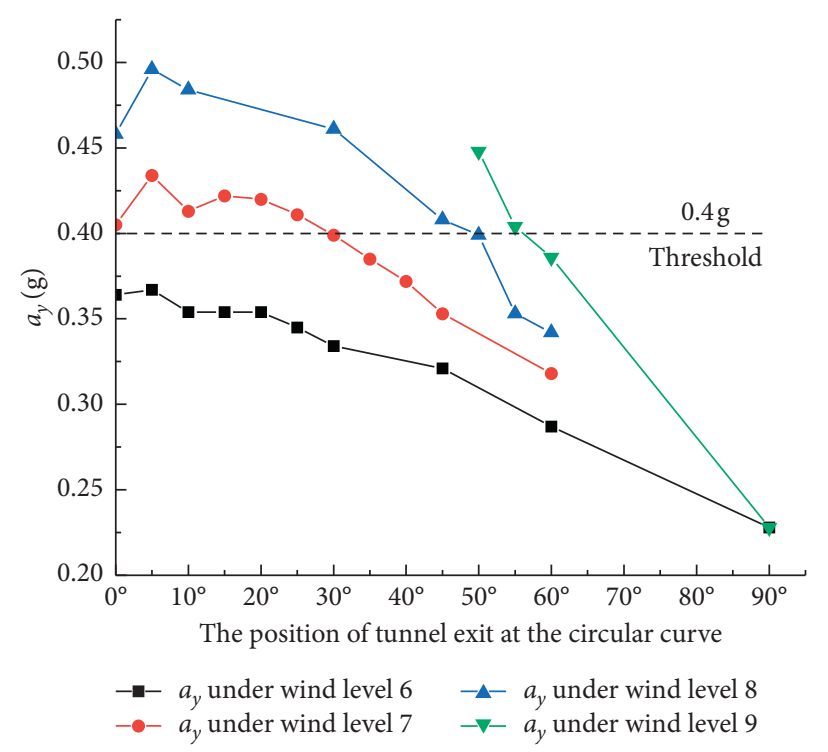

FIGURE 8: Lateral acceleration of the vehicle at different positions.

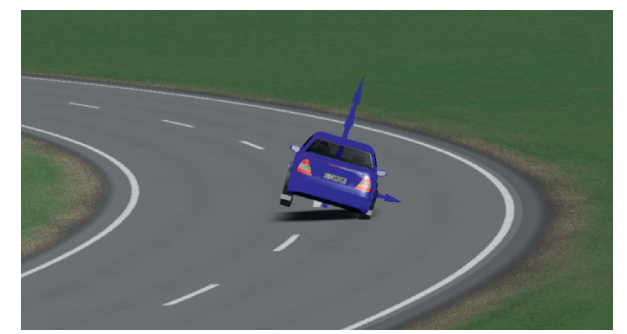

Figure 9: Vehicle roll over under level 9 wind scale.

TABLE 8: Data under level 5-9 wind scale.

\begin{tabular}{lcc}
\hline Wind scale & Unfavourable interval & Unfavourable position \\
\hline Level 5 & Stable & Stable \\
Level 6 & $0^{\circ} \sim 30^{\circ}$ & $5^{\circ}$ \\
Level 7 & $0^{\circ} \sim 35^{\circ}$ & $5^{\circ}$ \\
Level 8 & $0^{\circ} \sim 50^{\circ}$ & $5^{\circ}$ \\
Level 9 & $0^{\circ} \sim 60^{\circ}$ & $0^{\circ} \sim 45^{\circ}$ roll over \\
\hline
\end{tabular}

area the tunnel exit can be set at. After calculation, the proportion of tunnel exit's unfavorable interval of the circular curve under level 6 to level 9 wind scale is $33.33 \%$, $38.89 \%, 55.56 \%$, and $66.67 \%$, respectively. In addition, except that under the level 9 wind scale, the vehicle has experienced a significant rollover phenomenon when driving at 5 degrees on the circular curve. The vehicles under the level 6 to level 8 wind scale have the worst lateral stability when the tunnel exit is located at the circular curve of $5^{\circ}$. Therefore, the circular curve $5^{\circ}$ is considered to be the most unfavorable position of the tunnel exit. The summary of this unfavorable position of the tunnel exit can be used as 
auxiliary data for the design of mountainous highway tunnels. From the perspective of vehicle's lateral stability, it provides a reference for establishing a safer road environment.

\section{Discussion}

Based on the previous analysis, the safety of driving would be affected by several concepts, including road conditions, dynamic speed, the length of tunnels, the distance between tunnels, and the location of tunnel exit on the curve. Abstracting from the abovementioned survey, regardless of the vehicle model and road condition, wind would result in reduction of vehicles' absolute speed. Vehicles have higher lateral acceleration under the wind effects. It is more likely to cause a slip. Vehicle's $C_{S}$ value would be closer to the threshold when the radius of curve becomes smaller. The survey suggests that the crosswind would have the most impact when vehicles are passing the curve and that the angle between driving direction and the wind has a negative relation with driving safety. Moreover, the distance between two tunnels has a positive relation with driving safety that the longer the separation distance, the safer the drive would be.

Scholars have paid attention to the influence of crosswind on vehicle safety. Previous studies have demonstrated that, based on the principle of aerodynamics, the aerodynamic coefficient of vehicles would be affected by different wind speeds, wind directions, road scenes, vehicle geometry size, vehicle speeds, and other factors [32-34]. Generally, vehicle safety studies are carried out in the critical state of roll, sideslip, and overturn. The exit section of the tunnel is also the area that scholars pay attention to. When a vehicle enters the tunnel from the crosswind region, the aerodynamic loads on the vehicle would change sharply, which could increase the risk of overturning and sideslip accidents $[35,36]$. Most of the results are obtained by numerical simulation and wind tunnel test, providing more convenience and safety for researchers. However, this study is more persuasive by analyzing the data observed from the XiHan Highway. It should be noted that some of our conclusions are consistent with the previous studies qualitatively and verified by our measured data.

In view of the safe driving of vehicles under crosswind, it is feasible to optimize the aerodynamic performance by changing the vehicle shape and reduce the wind speed by setting wind barriers $[37,38]$. This study provides a new option to improve vehicle safety by optimizing road alignment. According to the results of data analysis, it will be helpful to ensure the fast and safe driving of vehicles in tunnel-group sections by increasing the radius of the circular curve and the distance between tunnels, or changing the location of the tunnel exit. Furthermore, it is determined that the lateral stability of the vehicle is the worst when the exit of the tunnel is located at 5 degrees of the circular curve under level 6 9 wind scale. Although the results are useful for accident prevention and traffic management under strong wind in the tunnel section of the mountainous expressway, there are still some deficiencies in the study. The quality of the observation data of the XiHan Highway varies. After screening, according to the research direction of this paper, the data for analyzing the internal law of the wind influence on vehicle's lateral stability is very limited, so the quantity and quality of the observed data need to be improved, and the radius of circular curve and the distance between tunnels need to be quantitatively studied to provide more accurate reference values.

China's development experiences show that to solve the problem of economic development of people living in mountain areas, the construction of expressways is one of the necessary measures, which can help people communicate and trade with the outside world more quickly. It is necessary to study the influencing factors on the lateral stability of vehicles to ensure that vehicles can run fast and safely on mountain expressways. The influence of crosswind on vehicles is not considered in China's road alignment design code, so the road alignment design method needs to be optimized. China's road alignment design code is consistent with that of other countries in basic theory. In the world's mainstream design codes and standards, most of them only consider the wind load in the design of long-span bridges, while the crosswind is not considered in the linear design of expressways. Therefore, although the results of this paper are based on the observation data of the Xi-Han Highway in China, it can also provide a theoretical reference for the design of mountainous highways in other regions of the world.

\section{Conclusion}

Nowadays in China, most of the highway design based on "Design Specification for Highway Route," does not consider the influence of wind on vehicle's driving safety. In this study, the data of selected driving vehicles from 15 selected positions on the Xi-Han Highway were collected and analysed. The software CarSim was utilized to do the simulation analysis to discuss how the different tunnel exit's location on the circular curve affect the vehicle's lateral stability. The results are as follows:

(1) For vehicles driving on mountainous expressways under strong wind, the driving speed, the radius of circular curve, the distance between tunnels, and the position of tunnel exit on the circular curve will affect the vehicles driving safety.

(2) Wind would result in reduction of vehicles' absolute speed. Vehicles have higher lateral acceleration under the wind effects. Vehicle's $C_{S}$ value would be closer to threshold when the circular curve becomes smaller. The survey suggests that the crosswind would have the most impact when vehicles are passing the curve and that the angle between driving direction and the wind has negative relation with driving safety. Moreover, the distance between two tunnels has positive relation with driving safety that the longer the separation distance, the safer the drive is. 
(3) Wind speed has an effect on the tunnel exit's unfavorable section on the circular curve. Considering the lateral stability of the vehicle, the influence mainly begins with the level 6 wind scale. The larger the wind level, the larger the proportion of the tunnel exit's unfavorable section on the circular curve, that is, the fewer safe areas can be set for the tunnel exit. After calculation, the proportions of tunnel exit's unfavorable section on the circular curve under 6-9 wind level are $33.33 \%, 38.89 \%, 55.56 \%$, and $66.67 \%$, respectively. In addition, besides the obvious rollover phenomenon of vehicles driving on the circular curve under level 9 wind scale, the lateral stability of vehicles under level 6-8 wind scale is the worst when the tunnel exit is located at the 5-degree area of circular curve, so the 5-degree area of circular curve is regarded as the most unfavorable location of the tunnel exit.

Therefore, the results of this paper can provide a basis for the design and operation of mountain highways. For mountainous highways that frequently encounter windy weather, at the design level, the small circular curve should be avoided as much as possible, and the separation distance between tunnels should not be too short. At the same time, it should avoid setting the tunnel exit at $5^{\circ}$ of the circular curves. In terms of operation, in case of windy weather above level 5 wind scale, the speed limit of the vehicles should be reduced accordingly. For the level 9 wind scale, the highway should be closed. This article can be applied to other mountainous highways. It optimizes the design of highway tunnel group sections and provides the theoretical and methodological basis for quantitative and scientific management of road traffic management departments.

Despite these contributions, there are still some aspects of the research that need to be optimized and improved. The limitations of the research are mainly resided in the quantity, quality, and accuracy of the simulation. The quantity and quality of the observed data need to be improved. In addition, the parameter settings of the vehicle model and the wind model in the simulation are relatively accurate, but in the road modeling, due to the uncertainty of the transition between the straight line and the circular curve, there is a case of simplified modeling. This paper aims to provide a universal method basis for the design of highway tunnel group sections. Therefore, in the data collection stage, multiple traffic environment, natural environment, and other highway section observation data suitable for the research content of this paper can be selected. The real roads in the form of the linear combination of various tunnel groups required for simulation are selected, and the relevant road line parameters are used as input values of the road model to improve the accuracy of the simulation.

\section{Data Availability}

The data used to support the findings of this study are available from the corresponding author upon request.

\section{Conflicts of Interest}

The authors declare that they have no conflicts of interest.

\section{Acknowledgments}

This work was supported by the China National Key R\&D Program during the 13th five-year plan period (2017YFC0803906); Fundamental Research Funds for the Central Universities of Ministry of Education of China (300102219111); and the Natural Science Basic Research Program of Shaanxi (2019JQ-146).

\section{References}

[1] T. L. Jackson and H. O. Sharif, "Rainfall impacts on traffic safety: rain-related fatal crashes in Texas," Geomatics, Natural Hazards and Risk, vol. 7, no. 2, pp. 843-860, 2016.

[2] A. T. Ibrahim and F. L. Hall, "Effect of adverse weather conditions on speed-flow-occupancy relationships," Transportation Research Record, vol. 1457, pp. 184-191, 1994.

[3] L. Ewan, A. Al-Kaisy, and D. Veneziano, "Remote sensing of weather and road surface conditions," Transportation Research Record: Journal of the Transportation Research Board, vol. 2329, no. 1, pp. 8-16, 2013.

[4] C. J. Baker and M. Sterling, "The calculation of train stability in tornado winds," Journal of Wind Engineering and Industrial Aerodynamics, vol. 176, pp. 158-165, 2018.

[5] H. Wan-Shui, "Safety assessment of moving vehicles on a long-span bridge under crosswind and influence factors analysis," Acta Aerodynamica Sinica, vol. 4, pp. 466-472, 2008.

[6] Y. Han, J. W. Huang, C. S. Cai, S. R. Chen, and X. H. He, "Driving safety analysis of various types of vehicles on longspan bridges in crosswinds considering aerodynamic interference," Wind and Structures, vol. 29, no. 4, pp. 279-297, 2019.

[7] G. Guang-Jun, T. Hong-Qi, and Z. Jia, "Cross-wind affection on double container train," Journal of Traffic and Transportation Engineering, vol. 4, no. 2, pp. 45-48, 2004.

[8] L. Wang, T. Xu, H. Xue, and D. W. Lu, "A simulation analysis of driving stability in crosswind condition on expressway in mountain areas," Journal of Transport Information and Safety, vol. 37, no. 3, pp. 20-27, 2019.

[9] T. Avadiar, J. Bell, D. Burton, H. Cormaty, and C. Li, "Analysis of high-speed train flow structures under crosswind," Journal of Mechanical Science and Technology, vol. 30, no. 9, pp. 3985-3991, 2016.

[10] S. Giappino, D. Rocchi, P. Schito, and G. Tomasini, "Cross wind and rollover risk on lightweight railway vehicles," Journal of Wind Engineering and Industrial Aerodynamics, vol. 153, pp. 106-112, 2016.

[11] X. Zhang and C. Proppe, "The influence of strong crosswinds on safety of different types of road vehicles," Meccanica, vol. 54, no. 9, pp. 1489-1497, 2019.

[12] C. J. Baker, "The quantification of accident risk for road vehicles in cross winds," Journal of Wind Engineering and Industrial Aerodynamics, vol. 52, pp. 93-107, 1994.

[13] H. Xiang, Y. Li, S. Chen, and C. Li, "A wind tunnel test method on aerodynamic characteristics of moving vehicles under crosswinds," Journal of Wind Engineering and Industrial Aerodynamics, vol. 163, pp. 15-23, 2017. 
[14] M. Batista and M. Perkovič, "A simple static analysis of moving road vehicle under crosswind," Journal of Wind Engineering and Industrial Aerodynamics, vol. 128, pp. 105113, 2014.

[15] J. Fuller, M. Best, N. Garret, and M. passmore, "The importance of unsteady aerodynamics to road vehicle dynamics," Journal of Wind Engineering and Industrial Aerodynamics, vol. 117, pp. 1-10, 2013.

[16] L. Wang, "Traffic safety study of mountain highway bridge and tunnel connecting segment under the wind environment," M. S. thesis, Chang'an University, Xi'an, China, 2014.

[17] L. Wang and H. Chen, "Study on traffic safety and wind environmental improvement at canyon bridge and tunnel connection segment," Journal of Wuhan University of Technology, vol. 34, pp. 957-962, 2012.

[18] J. L. Xu, H. Wang, L. P. Zhao, and Y. J. Han, "Research on minimum radius of highway horizontal curve with crosswind considered," China Journal of Highway and Transport, vol. 27, no. 1, pp. 38-43, 2014.

[19] J. Freund and T. Poschel, "A statistical approach to vehicular traffic," Physica A: Statistical Mechanics and its Applications, vol. 219, no. 1-2, pp. 95-113, 1995.

[20] F. H. Amundsen and C. Ranes, "Studies on traffic accidents in Norwegian road tunnels," Tunnelling and Underground Space Technology, vol. 15, no. 1, pp. 3-11, 2000.

[21] W. K. Chow, "Simulation of tunnel fires using a zone model," Tunnelling and Underground Space Technology, vol. 11, no. 2, pp. 221-236, 1996.

[22] M. Zhuanglin, "Evaluation indices for traffic environment of expressway tunnel," Journal of Chang'an University, vol. 2, pp. 77-80, 2006.

[23] N. Ni, S. W. Yang, B. H. Pan, and L. Wang, "Traffic accident characteristics and prevention measures for the zhongnanshan highway tunnel," Modern Tunnelling Technology, vol. 55, no. 4, pp. 25-32, 2018.

[24] H. Sun, Q. P. Wang, P. Zhang, Y. J. Zhong, and X. B. Yue, "Spatialtemporal characteristics of tunnel traffic accidents in China from 2001 to present," Advances in Civil Engineering, vol. 2019, Article ID 4536414, 12 pages, 2019.

[25] A. H. Huang, "The traffic safety analysis and improvement measure research on sections of bridges and tunnels," M. S. thesis, Chang'an University, Xian, China, 2017.

[26] F. Zhongquan, "Study on speed limit technology of freeway tunnel group in mountainous area," M. S. thesis, Chang'an University, Xian, China, 2017.

[27] H. Song, "The research of operation safety technology based on alignment design of highway tunnel group," M. S. thesis, Chang'an University, Xian, China, 2011.

[28] P. Hu, Y. Li, Y. Han et al., "Numerical simulations of the mean wind speeds and turbulence intensities over simplified gorges using the SST k-omega turbulence model," Engineering Applications of Computational Fluid Mechanics, vol. 10, no. 1, pp. 361-374, 2016.

[29] X. Y. Chen, Z. W. Liu, X. G. Wang et al., "Experimental and numerical investigation of wind characteristics over mountainous valley bridge site considering improved boundary transition sections," Applied Sciences, vol. 10, no. 3, p. 751, 2020.

[30] L. Fan, G. Y. Li, R. Chen et al., "Calculation of lateral force coefficient and turning radius for bus cornering stability under extreme turn conditions," Journal of South China University of Technology, vol. 45, no. 2, pp. 39-45, 2017.

[31] A. Gauchía, E. Olmeda, F. Aparicio, and V. Díaz, "Bus mathematical model of acceleration threshold limit estimation in lateral rollover test," Vehicle System Dynamics, vol. 49, no. 10, pp. 1695-1707, 2011.

[32] F. Cheli, R. Corradi, E. Sabbioni, and G. Tomasini, "Wind tunnel tests on heavy road vehicles: cross wind induced loadspart 1," Journal of Wind Engineering and Industrial Aerodynamics, vol. 99, no. 10, pp. 1000-1010, 2011.

[33] F. Cheli, F. Ripamonti, E. Sabbioni, and G. Tomasini, "Wind tunnel tests on heavy road vehicles: cross wind induced loadspart 2," Journal of Wind Engineering and Industrial Aerodynamics, vol. 99, no. 10, pp. 1011-1024, 2011.

[34] B. Wang and Y.-L. Xu, "Safety analysis of a road vehicle passing by a bridge tower under crosswinds," Journal of Wind Engineering and Industrial Aerodynamics, vol. 137, pp. 25-36, 2015.

[35] W. Yang, E. Deng, M. Lei, P. Zhang, and R. Yin, "Flow structure and aerodynamic behavior evolution during train entering tunnel with entrance in crosswind," Journal of Wind Engineering and Industrial Aerodynamics, vol. 175, pp. 229243, 2018

[36] F. Chen, H. Peng, X. Ma et al., "Examining the safety of trucks under crosswind at bridge-tunnel section: a driving simulator study," Tunnelling and Underground Space Technology, vol. 92, Article ID 103034, 2019.

[37] S. Mansor and M. A. Passmore, "Effect of rear slant angle on vehicle crosswind stability simulation on a simplified car model," International Journal of Automotive Technology, vol. 14, no. 5, pp. 701-706, 2013.

[38] C.-R. Chu, C.-Y. Chang, C.-J. Huang, T.-R. Wu, C.-Y. Wang, and M.-Y. Liu, "Windbreak protection for road vehicles against crosswind," Journal of Wind Engineering and Industrial Aerodynamics, vol. 116, pp. 61-69, 2013. 